\title{
OS ACIDENTES MORTAIS RELACIONADOS COM OS INCÊNDIOS FLORESTAIS EM PORTUGAL, NO VERÃO DE 2003
}

\author{
Domingos Xavier Viegas ${ }^{1}$
}

\section{INTRODUÇÃO}

Os incêndios florestais ocorridos em Portugal no ano de 2003 foram os mais graves de que existe registo, em termos de área ardida, de devastação produzida e de perdas de vidas humanas. Entre todas as perdas causadas pelos incêndios, são as perdas humanas e em particular as mortes as que mais irão marcar os acontecimentos do Verão de 2003, não apenas pelo número e diversidade de acidentes ocorridos, ams também pelo elevada percentagem de mortes ocorridas entre elementos da população civil.

Neste artigo o autor analisa os acidentes relacionados com os IF, que deram origem a perda de vidas. Este texto resume os relatos deste acidentes que se encontram em Viegas (2004).

\section{Alguns Dados}

A evolução do número de incêndios ocorridos anualmente em Portugal, entre 1970 e 2003 mostra-se na figura 1. Como se pode ver este número tem vindo a crescer regularmente, com uma média anual da ordem de 28000 ocorrências; é de notar que no ano de 2003 o número de incêndios registado foi significativamente inferior ao dos anos anteriores.

As áreas ardidas anualmente, no mesmo período, encontram-se representadas na figura 2. A tendência de crescimento da área ardida, a partir de 1975, tem coexistido com uma elevada variação interanual. A média dos últimos anos centrava-se em cerca de $100 \mathrm{kHa}$, mas no ano de 2003 a área ardida superou os $430 \mathrm{kHa}$, ou seja cerca de quatro vezes tal média e mais do que o dobro do que o pior ano, de que há registo (1991).

Esta grave crise foi devida a um período de seca excepcionalmente grave no interior de Portugal, entre os meses de Maio e de Setembro, que se seguiu a um Inverno e Primavera muito chuvosos, com precipitação média superior em $50 \%$ aos valores normais. Em dois períodos de Agosto e de Setembro ocorreram duas ondas de calor, com temperaturas excepcionalmente elevadas e valores da humidade relativa muito baixos.

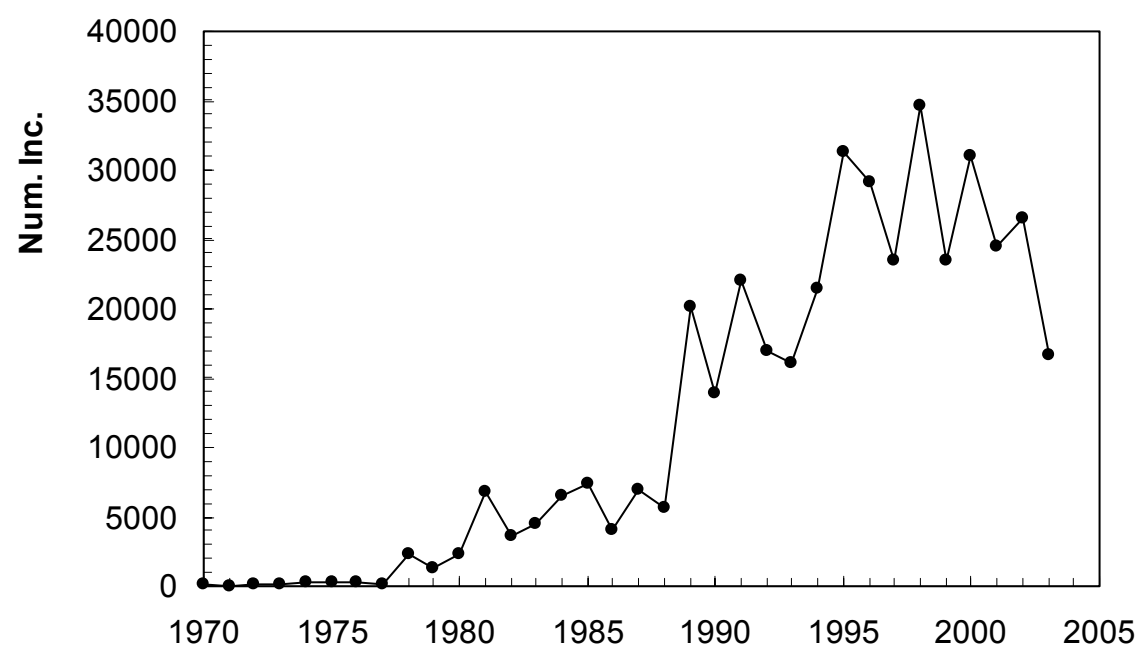

Figura 1: Evolução do número de incêndios registrados anualmente em Portugal, desde 1970 até o presente

${ }^{1}$ xavier.viegas@dem.uc.pt 
Viegas, D. X.

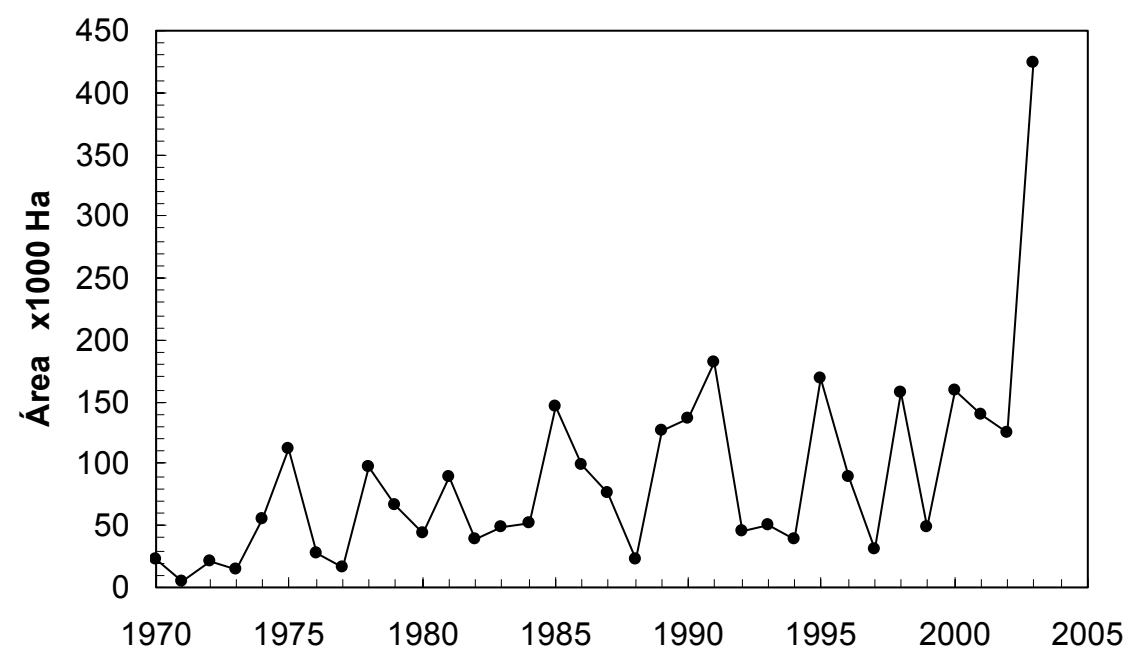

Figura 2: Evolução da área ardida anualmente em Portugal, desde 1970 até o presente

Em consequência da intensidade de propagação dos incêndios, verificaram-se muitos acidentes mortais, cuja localização geográfica se mostra na figura 3.

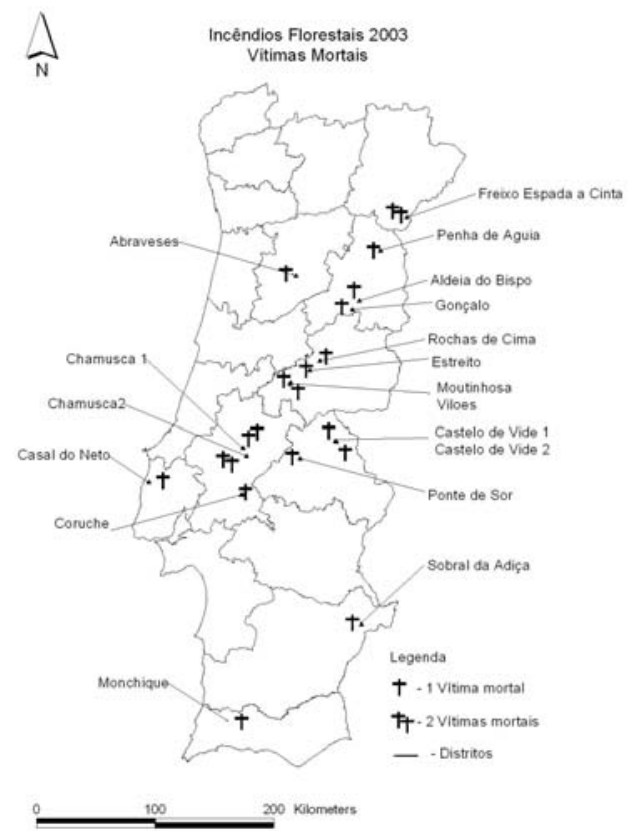

Figura 3: Localização geográfica de cada um dos dezoito acidentes em que ocorreram fatalidades relacionadas com os incêndios florestais, no ano de 2003

\section{Breve Relato dos Acidentes}

Coruche

Este acidente ocorreu no dia 19 de Junho, em Coruche, no distrito de Santarém. Foi vítima um pastor de 83 anos, que estava a guardar o seu rebanho e que devido ao calor, estaria a descansar, não se tendo apercebido de um foco de incendio produzido a cerca de um quilómetro do local em que se encontrava. Quando se deu conta e tentou retirar com o rebanho, não teve tempo de fugir, sendo surpreendido pela rápida progressão das chamas na vegetação herbácea da clareira em que se encontravam, cerca das $15.00 \mathrm{~h}$. 


\section{Rochas de Cima}

Neste acidente, que ocorreu no dia 29 de Julho, em Rochas de Cima, no distrito de Castelo Branco, pelas $18.00 \mathrm{~h}$, faleceu um homem de 79 anos de idade que estava sózinho a vigiar uma propriedade florestal ameaçada por um incêndio. Foi surpreendido pelo fogo quando se retirava em direcção a um campo agrícola, perto da povoação, onde se encontrava um grupo de populares e alguns bombeiros a combater o fogo, procurando proteger a aldeia. Não está esclarecido se a frente de chamas que vitimou este proprietário era a frente principal ou se outra produzida por um foco secundário ou por um contra-fogo.

\section{Estreito}

Neste acidente, que ocorreu no dia 30 de Julho, no Estreito, no distrito de Castelo Branco, pelas $18.00 \mathrm{~h}$, faleceu um homem de 81 anos de idade que estava na sua viatura a percorrer uma propriedade florestal ameaçada por um incêndio. Quando este se aproximava, descendo uma encosta do outro lado do vale em que se encontrava, decidiu retirar-se na viatura, subindo uma estrada florestal, em direcção à estrada principal. A propagação do fogo foi no entanto muito mais rápida do que ele poderia ter previsto e viu o seu caminho barrado por uma frente que subira um desfiladeiro. Sem retirada possível, permaneceu dentro da viatura, que foi completamente destruida pelo fogo.

Sobral da Adiça

Este acidente ocorreu no dia 1 de Agosto, proximo de Sobral da Adiça, distrito de Beja, e vitimou um trabalhador com 67 anos de idade. Este pertencia a um grupo de pessoas que estiveram a almoçar numa área de recreio e que estaria debilitado fisicamente pelo calor e pelo excessivo consumo de vinho. Ao ser dado o alarme, cerca das $17.00 \mathrm{~h}$, devido a um incendio iniciado a cerca de $600 \mathrm{~m}$ do local em que se encontravam, não reagiu à indicação dos colegas para fugirem. Quando estes se retiraram em pânico, não os conseguiu acompanhar, tendo sido colhido pelas chamas que avançaram rapidamente em vegetação herbácea e mato muito secos que havia em volta. Quando mais tarde alguns homens voltaram para o socorrer já era tarde. Havia sofrido queimaduras muito graves, em resultado das quais viria a falecer, no dia 6 de Agosto.

Gonçalo

Neste acidente, que ocorreu num lugar perto de Gonçalo, distrito da Guarda, no dia 2 de Agosto, seria vítima uma senhora de 71 anos de idade. Encontrando-se sózinha em casa decidiu ir para casa de uns vizinhos, ao pressentir a aproximação de um incêndio no fundo do vale em que a sua casa se encontrava. No caminho, quando se encontrava ainda muito perto da sua casa, foi supreeendida pelo rápido avanço das chamas pela encosta. Com a deslocação do ar caiu no chão e sofre uma fractura, tendo dificuldade em se levantar. Durante o tempo em que esteve caída ficou exposta ao calor e sofreu queimaduras graves. Foi transportada ao hospital e socorrida numa unidade especializada para o tratamento de queimados. Apesar dos cuidados, viria a falecer no dia 14 de Agosto, devido à gravidade das queimaduras.

Pinheiro Grande

No concelho de Chamusca, distrito de Santarém, no dia 2 de Agosto diversas descargas de trovoadas originaram cerca de dez incendios muito graves. Um desses incendios viria a atingir o lugar de Pinheiro Grande onde residiam duas senhoras, em casas contíguas, uma com 35 anos e outra com 67 anos. Apesar de terem sido aconselhadas a deixar as casas algum tempo antes de o incêndio se aproximar, decidiram ficar. Quando o fogo se aproximou e finalmente decidiram fugir, foram as duas juntas a pé pela estrada procurando afastar-se do incêndio. Quando estavam a chegar junto de outra casa próxima, que não chegou a ser destruida pelo fogo, viriam a ser colhidas pelo calor e pelo fogo, vindo a morrer ambas na estrada.

\section{Casal de Paires}

No mesmo Concelho e no mesmo dia 2 de Agosto, noutro local, perto de Casal de Paires, viriam a falecer dois técnicos de combate de nacionalidade Chilena, um de 43 anos e outro de 29 anos. 
Faziam ambos parte de uma brigada de dez homens pertencentes a uma empresa de protecção florestal, que trabalhava para a Aliança Florestal. Este grupo estivera a proteger uma plantação de Eucalipto quando foi chamada a retirar-se para ir para outra zona do País. No seu trajecto para o local de encontro com o meio de transporte, percorreram cerca de seis quilometros a pé, em direcção a Casal de Paires. Quando se aproximavam desta lugar aperceberam-se de um foco de incendio que se aproximava da estrada em que seguiam. O chefe da brigada deu ordem para apressarem o passo, mas um dos combatentes, com grande experiência, não atendeu a ordem e foi acompanhado nesse comportamento por um companheiro mais jovem, tendo se ambos atrasado, em relação ao restante grupo. A certo ponto encontraram a estrada cortada pelo fogo e refugiaram-se por uma outra estrada que descia em direcção a um pequeno vale. Infelizmente esta estrada, que inicalmente parecia afastalos do incendio de que fugiam, acabava por inflectir em direcção a uma zona sem saída, por estar completamente rodeada pelo fogo. Tentaram recuar, mas não conseguiram ultrapassar uma pequena encosta que os separava de uma extensão de água que lhes poderia ter proporcionado refúgio.

\section{Ponte de Sôr}

Em resultado deste acidente ocorrido no Concelho de Ponte de Sôr, distrito de Santarém, no dia 2 de Agosto, veio a falecer um homem de 52 anos, tractorista, que juntamente com o seu filho tentava combater um incêndio na herdade agrícola em que trabalhava. Ao verem que nada podiam fazer face ao avanço do fogo decidiram fugir no tractor que tinha uma cabina fechada, em que seguiam os dois. Em determinada altura, devido ao fumo, sairam do caminho e chocaram com uma árvore, tendo o tractor ficado danificado, mas não inutilizado. Decidiram sair do tractor e prosseguir a pé, para fugir ao incêndio. Um pouco mais adiante o tractorista, que possivelmente terá ficado ferido ou combalido com o choque do tractor, ao não ter forças para prosseguir, insistiu com o filho para fugir, em busca de socorro para ele. Com dificuldade ainda andou alguns metros, em busca de refúgio, mas viria a ser atingido pelo fogo, muito antes de o filho poder voltar com socorros.

\section{Castelo de Vide 1}

Neste acidente, ocorrido em 3 de Agosto, no concelho de Castelo de Vide, distrito de Portalegre, seria vítima um bombeiro de 45 anos, dos bombeiros Voluntarios de Castelo de Vide. Fazia parte de um grupo de cinco bombeiros, que foram na sua viatura para combater um incêndio em vegetação herbácea num pequeno vale. Quando se preparavam para ir combater as chamas, num golpe de vento estas progrediram muito rapidamente e vieram ao seu encontro. Tiveram de subir para a viatura e fugir em dificuldade. Um dos bombeiros, ao não conseguir subir para a viatura ficou para trás e foi refugiar-se num conjunto de rochas com alguns arbustos. A aproximação do fogo a este local provocou-lhe queimaduras graves, de que viria a falecer no dia 14 de Agosto.

\section{Castelo de Vide 2}

Este acidente ocorreu no mesmo incendio que o anterior e a cerca de um quilómetro do mesmo. Foi vítima um agricultor de 48 anos que se dirigia no seu tractor, por uma estrada principal para combater o fogo e impedir o seu avanço, em propriedades próximas daquele local. Ao passar numa curva da estrada foi surpeeendido pelo avanço do fogo que o atingiu, tendo o tractor começado a arder quase imediatamente. Saltou do tractor e foi correndo pela estrada, para se afastar da frente principal do incêndio. Por casualidade foi socorrido por um amigo que se encontrava parado perto da estrada, procurando ajudar. Foi levado para o hospital, mas devido às graves queimaduras que sofrera veio a falecer também no dia 14 de Agosto.

\section{Vilões}

Neste acidente, ocorrido em Vilões, no distrito de Castelo Branco, no dia 3 de Agosto, faleceu uma senhora de 69 anos, residente numa casa isolada no meio da floresta, perto da aldeia. Com a aproximação do incêndio foi buscar umas mangueiras que tinha num terreno agrícola junto da aldeia. No percurso de regresso, ao atravessar o pinhal e quando se encontrava a menos de 200 metros de casa, foi surpeendida pelo incêndio. Largando as mangueiras procurou fugir pelo meio da vegetação, mas foi supreendida por nova frente de fogo que a viria a vitimar. 
Moutinhosa

Neste acidente, ocorrido na Moutinhosa, distrito de Castelo Barnco, no mesmo dia do anterior e a cerca de dois quilómetros do local de ocorrência do mesmo, veio a falecer um proprietário florestal, de 53 anos de idade. Com a aproximação do incêndio procurou organizar um grupo de defesa da aldeia. Tendo-se proposto combater o incêndio no fundo de um vale, verificando que a violência do incêndio ao descer a encosta oposta era tal, que se tornava perigoso combate-lo naquele local, terá então decidido retirar para a aldeia. Ao fazer este percurso, a pé, foi supreendido pelo rápido avanço das chamas pela encosta, que lhe cortou o caminho para a aldeia. Decidiu então tomar outra estrada em direcção a um outro vale, do lado oposto de onde vinha. Mas também nesta encosta foi surpeeendido por uma nova frente da qual não pode fugir.

Penha de Águia

Neste acidente, ocorrido em Penha de Águia, no distrito da Guarda, no dia 6 de Agosto, faleceu um bombeiro dos BV de Figueira de Castelo Rodrigo. Era o condutor de um auto tanque que se dirigia para combater um incendio florestal proximo de Penha de Águia, quando ao descer um estrada ingreme e em curva, perdeu o controle do veiculo, que saiu da estrada e caiu na ribanceira. Do acidente resultou a morte do motorista e ferimentos nos restantes ocupantes do veículo.

Aldeia do Bispo

Uma senhora de 39 anos, foi vitima deste acidente ocorrido em Aldeia do Bispo, distrito da Guarda, no dia 7 de Agosto. Era funcionária de um centro social, onde cuidava de pessoas idosas, que ali passavam o dia. Com a aproximação de um incêndio em relação à aldeia ajudou a retirar os idosos para as suas casas e voltou depois para ajudar a proteger o centro. Com a chegada de um grupo de bombeiros da Guarda, foi ajudá-los no seu esforço por evitar que o incêndio atingisse e danificasse o centro e alcançasse a aldeia. Surpreendendo todos o fogo atravessou rapidamente o vale em que estava a lavrar e subiu a encosta em que se encontravam, com muita violência. $\mathrm{O}$ grupo de bombeiros e alguns populares, entre os quais se encontrava a senhora, tiveram de fugir em pânico, para a estrada em frente do centro. Ao não se encontrar em segurança naquele local e temendo pela segurança da sua casa nova, decidiu dirigir-se para ela, a fim de a proteger também. Neste percurso, ao atravessa um zona de mato alto, foi surpreendida pelo fogo, possivelmente de uma outra frente, que rodeara a encosta e faleceu a menos de 20 metros de um local onde poderia ter encontrado abrigo e salvação.

Freixo de Espada-à-Cinta

Neste acidente, ocorrido a 7 de Agosto, em FEC, distrito de Bragança, veio a falecer um casal de proprietários florestais, com 50 e 40 anos, que fora observar o incêndio e para se assegurar que as suas propriedades estavam a salvo do mesmo. O incêndio inciara-se numa encosta sobre o Rio Douro, com um coberto de vegetação arbustiva e de vegetação agricola. Estivera a ser combatido pelos BV de FEC e estava praticamente circunscrito na parte inferior da encosta, perto da margem do rio, quando ocorre uma erupção, com um crescimento súbito do fogo, que veio a percorrer toda a encosta, atingindo mesmo o casal que se encontrava a mais de um quilómetro do local em que se iniciou a erupção.

\section{Santa Cruz}

Neste acidente ocorrido em Santa Cruz, distrito de Lisboa, no dia 23 de Agosto, viria a falecer um ancião de 69 anos. Perto do meio dia havia realizado uma pequena queimada num terreno agrícola, a qual não oferecia grande perigo. Ao ser realizada em época de incendios, era naturalmente proibida, pelo que o senhor terá tentado fazê-la sozinho. Ao querer controlar as chamas, devido à dificuldade de movimentação que tinha, viria a cair no meio do fogo falecendo prontamente. A área total da queimada foi de uns escassos 30 por 50 metros quadrados.

\section{Monchique}

Neste acidente, que ocorreu na madrugada do dia 12 de Setembro, durante a segunda vaga de incêndios que devastou o concelho de Monchique, no distrito de Faro, viria a perder a vida um 
habitante de um pequena aldeia, de 58 anos de idade. A sua casa já havia sido atingida por um grande incêndio no Verão de 1995, tendo perdido um automóvel que foi destruido pelo fogo. Desta vez havia preparado tudo para se retirar no seu automovel quando o incêndio se aproximou da aldeia. Infelizmente não o fez a tempo, uma vez que foi surpeendido pelo fogo quando se dirigia para a garagem situada a acerca de 300 metros da sua casa. Para fugir do incendio desceu por uma ravina, que não se encontraria ainda a arder, dirigindo-se para um local baixo que the pudesse dar refúgio ou possibilidade de se afastar mais do incêndio. A propagação rápida das chamas viria a atingi-lo num local, no meio da vegetação, onde não dispunha de quaisquer recursos para se proteger e salvar.

\section{Abravezes}

Neste acidente, ocorrido no mesmo dia, poucas horas depois, em Abravezes, no distrito de Viseu, perdeu a vida uma anciã de 78 anos, que foi vítima de uma queimada que ela propria iniciara. Tendo a necessidade de queimar uns resíduos florestais e agrícolas que tinha juntado na orla de um pinhal junto de sua casa, ao saber que eram proibidas as queimadas durante o Verão, decidiu-se a fazêla sózinha e muito cedo na madrugada. Ao ver passar dois homens na estrada perto do pinhal, para não ser denunciada afastou-se da fogueira, para se esconder por trás de uns pinheiros que estavam perto. Os dois homens que passavam na estrada viram o clarão da fogueira e deram o alarme aos bombeiros, mas por não terem visto qualquer presença humana, afastaram-se, entre outras razões para não serem tomados por causadores do foco de incêndio. Entretanto o fogo saiu de controle e a pequena fogueira alastrou pelo mato, vindo a atingir a anciã. Quando os bombeiros chegaram e apagaram com facilidade o fogo, este não tinha destruido mais do que uns $20 \times 50 \mathrm{~m} 2$ de mato. Uma vez mais havia ocorrido uma morte absurda e perfeitamente evitável.

\section{CONCLUSÃO}

Os incêndios do Verão de 2003, em Portugal, produziram, entre outros danos, vinte e uma fatalidades. Cada um destes acidentes é rico em ensinamentos acerca do comportamento do fogo e das pessoas. A incorporação destas lições, por parte da estrutura responsável pelas acções de prevenção e de combate dos incêndios florestais em Portugal e a sua comunicação aos agentes operacionais e à população em geral deveria ser um imperativo, no sentido de se fomentar uma melhor cultura de segurança pessoal no nosso País.

\section{AGRADECIMENTO}

$\mathrm{O}$ autor deseja agradecer aos seus colaboradores e às pessoas e instituições que deram o seu contributo para a investigação dos acidentes referidos. O apoio dado pela União Europeia e pela Fundação para a Ciência e Tecnologia para o programa de investigação que dirige, no âmbito do qual se realizou o presente estudo, é também reconhecidamente mencionado.

\section{BIBLIOGRAFIA}

D. X. Viegas 2004 - Cercados pelo Fogo, Editorial Minerva, Coimbra, 283 pp. 